\title{
Particle Distribution, Film Formation and Wear Performance of Brush Plated Ni/WC
}

\author{
L. Isern, ${ }^{1}$ S. Impey, ${ }^{1}$ S. J. Clouser, ${ }^{2, *}$ D. Milosevic, ${ }^{2, *}$ and J. L. Endrino ${ }^{1, z}$ \\ ${ }^{1}$ School of Aerospace, Transport and Manufacturing (SATM), Cranfield University, MK43 OAL Cranfield, \\ Bedfordshire, United Kingdom \\ ${ }^{2}$ SIFCO ASC, Independence, Ohio 44131, USA
}

\begin{abstract}
Nickel-matrix composite coatings with tungsten carbide particles were produced by brush electroplating using different current densities and materials of the brush. Non-abrasive materials and high current densities produce coatings with high particle content and non-uniform dispersion. Abrasive wear testing showed premature coating failure in areas with high particle concentrations ( $>21.3$ at.\% of W). Changes to the solution flow direction were undertaken to decrease 'solution pooling', as it was related to areas with excessive particle content. This, together with the use of abrasive brushes at lower current densities, gives Ni/WC coatings with a low and narrow composition range (from $13.2 \pm 4.8$ to $2.8 \pm 0.8$ at.\% of W). Such optimized coatings minimized premature coating failure and improved the wear resistance to 1.8-4.4 times that of the original nickel matrix, achieving values similar to hard chrome coatings tested under the same conditions. Unlike other brush plated composite coatings, changes in coating morphology are not heavily influenced by processing parameters, but are sensitive to the presence of WC particles.

(C) The Author(s) 2018. Published by ECS. This is an open access article distributed under the terms of the Creative Commons Attribution 4.0 License (CC BY, http://creativecommons.org/licenses/by/4.0/), which permits unrestricted reuse of the work in any medium, provided the original work is properly cited. [DOI: 10.1149/2.1161809jes]

(cc) BY
\end{abstract}

Manuscript submitted April 4, 2018; revised manuscript received June 5, 2018. Published June 16, 2018.

Finding safer, eco-friendly alternatives to hard chrome plating has been a main driver of electroplating research for the last decade. The outstanding hardness and tribological properties of the hard chrome coating make it attractive for applications requiring wear resistance. In addition, the plating process is relatively simple and inexpensive, favoring the widespread use of this coating system for automotive, aeronautical, and engineering applications. However, there are also disadvantages associated with hard chrome, mainly related to the plating efficiency and the use of hexavalent chromium salts. For example, chrome plating has low cathode efficiency, ${ }^{1}$ which results in low throwing power and relatively slow material deposition rates coupled with additional evolution of gases resulting from the low process efficiency. Additionally, the plating solution contains hexavalent chromium salts, which are a known human carcinogen and detrimental to the environment. Due to manufacturing health and safety concerns, legislation regarding chrome plating production is restrictive, involving strict controls. Major limitations on its production and use in the EU were enacted on late 2017. Both production inefficiency and health and safety concerns are powerful incentives to produce viable alternatives, and in recent years a significant amount of research has been steered in this direction. Different electroplated materials have been proposed as candidates, including new alloys (such as Ni-W ${ }^{2}$ and Ni-Mo-Co) ${ }^{3}$ and specially Metal Matrix Composites. ${ }^{4-6}$

Metal matrix composite (MMC) coatings are formed during a process called co-deposition. If solid particles are suspended in the plating solution, they can be trapped by the depositing ions and so incorporated into the coating. ${ }^{7,8}$ Particle co-deposition can be assisted by manipulating the surface charge of the particles, which will attract them to the plating surface by electrophoresis, for example using surfactants. ${ }^{9}$ The coating is then formed of two phases, a ductile metallic matrix deposited from the dissolved ions in the solution, and a dispersed phase made out of the co-deposited particles. By choosing the right combination of materials, the properties can be tailored beyond the possibilities offered by metals and alloys alone. MMC coatings can be deposited using electroplating techniques, such as brush plating. Studies of brush plated MMCs to produce hydrophobic surfaces and or reduce friction revolve around the production of Ni/PTFE. ${ }^{10,11}$ Another interesting possibility is the addition of hard particles, such as oxides or carbides, to enhance the hardness and wear resistance of the coating. Some systems have reported improved mechanical and tribological performance, such as $\mathrm{Ni} / \mathrm{Al}_{2} \mathrm{O}_{3}{ }^{12,13}$ and $\mathrm{Co} / \mathrm{Cr}_{3} \mathrm{C}_{2}{ }^{14}$

*Electrochemical Society Member.

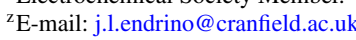

However, most MMC research has been undertaken using traditional electroless and electroplating processes, often combining matrices of pure nickel, nickel alloys or chromium (from trivalent baths) with oxide or carbide as the dispersed phase. The most usual combination is $\mathrm{Ni} / \mathrm{SiC}$, but other systems are also reported, such as $\mathrm{Ni} / \mathrm{WC}, \mathrm{Ni} / \mathrm{Al}_{2} \mathrm{O}_{3}$, $\mathrm{Cr} / \mathrm{WC}$ and $\mathrm{Ni} /$ diamond. These systems have successfully deposited coatings on a laboratory scale, reporting significant improvements in the mechanical and tribological properties compared to the original matrix.

Brush plating, or selective plating, is an electrodeposition technique that does not require the use of tanks, features portability and is characterized by the use of a brush to deliver the electroplating solution to the cathodes. The brush, a non-soluble anode, is enveloped by an electrically insulating cloth, for example Scotch-Brite, soaked in the electrolytic solution. The metal ions in solution are therefore in direct contact with both electrodes, allowing the electrodeposition process to take place. The insulating brush prevents direct contact between the electrodes, avoiding a short-circuit. ${ }^{15}$ The part to be coated does not need to be submerged in a tank or disassembled, plating can take place on-site. Localized deposition occurs when the brush is in contact with the part, an electric potential is established between the two, and the solution is distributed to the brush. For the solution distribution, the brush can be either dipped in the solution or a pumping system can collect and re-circulate the solution. Selective plating is simplified by direct contact with brush and part, and small, selected areas can be isolated from the rest of the component using considerably less masking. Other advantages over tank plating are the use of smaller volumes of solution, the portability of the process and higher deposition rates due to the use of higher current densities (usually $10 \mathrm{x})$. Brush plating usually produces harder coatings. ${ }^{16-18}$ Constant movement between anode and cathode is required to avoid overheating the electrolyte and to provide a good surface finish. ${ }^{15}$ Although most plating is carried out manually, currently automated brush plating using a rotating electrode ${ }^{2,19,20}$ and robotic arm $^{21}$ are commercially available. Brush plating is widespread in aerospace, automotive, and engineering industries for on-site repairs, plating specific areas of large parts (selective plating) and fast plating of small and medium sized components. Traditionally, brush plating has been used to deposit metals ${ }^{22,23}$ and alloys, ${ }^{2,24}$ but recent years have seen an increased interest in MMC coatings.

This paper analyzes the deposition and characterization of $\mathrm{Ni} / \mathrm{WC}$ coatings by brush electroplating as a potential replacement to hard chrome. The production of the $\mathrm{Ni} / \mathrm{WC}$ coatings is of interest due to the existing literature reports on tank plating about the promising tribological performance of this composite, and due to the 
(a)

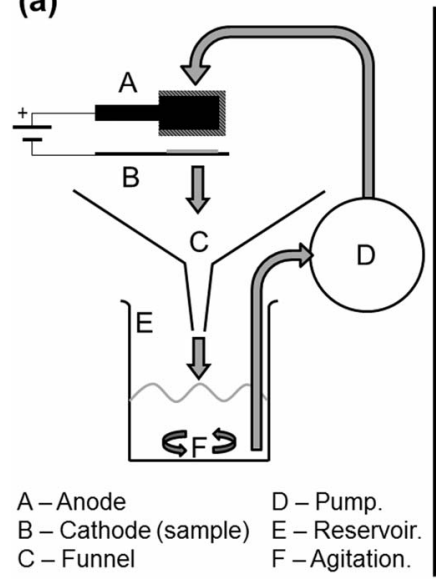

(b)

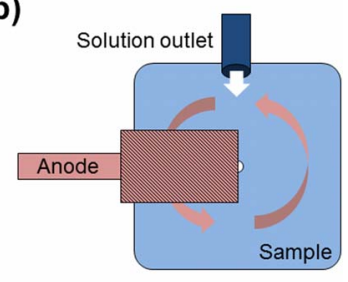

(c)

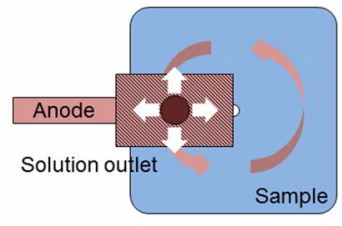

Figure 1. Schematic of the solution circulation setup (a) with detail of the solution outlet attached to (b) the side of the sample or (c) the anode.

outstanding wear resistance of $\mathrm{Ni} / \mathrm{WC}$ cemented carbide systems..$^{25,26}$ In this work, the composite $\mathrm{Ni} / \mathrm{WC}$ coatings were deposited using a range of current densities and brush materials to assess their impact on coating homogeneity and mechanical performance.

\section{Experimental}

Brush plating setup.-The setup used for brush plating comprises a rectifier, a brush-covered anode, and a pumped flow loop to circulate the solution. The rectifier was a model pe2010 manufactured by plating electronic (Germany). The anodes are inert, either a graphite block or a titanium mesh coated with iridium oxide. The anodes were covered by one of three different $3 \mathrm{M}$ Scotch-Brite cloths ${ }^{27}$ known as brush materials, referred according to their color for simplicity; two abrasive cloths (Red (7447) and Purple (2565)) due to the abrasive particles embedded within, and the third, a particle-free non-abrasive cloth (White (7445)).

The circulating system was designed for MMC deposition: the particle transportation was optimized to promote a steady solution flow through the system and the reservoir agitated to keep the particles in suspension. The design is based on a previous study ${ }^{28}$ and, as shown in Figure 1a, features a steep-walled funnel to collect spills and excess liquid, a reservoir fed by the funnel where the liquid is under constant stirring to prevent particle sedimentation, and a pump circulating liquid from the reservoir to the anode. Two variants of this design were used in this research:

- Magnetically-stirred: used for small volumes of solution (up to 1 1). The magnetic stirring prevents particle sedimentation in the reservoir and a peristaltic pump circulates the solution.

- Air-stirred: used for larger volumes of solution (up to 4 1) with compressed-air in the reservoir for stirring and a magnetically coupled centrifugal pump to circulate the solution.

Finally, the tube that comes from the pump and emerges on the substrate area to be plated can be either attached to the side of the sample (Figure 1b) or to the anode which will move across the sample (Figure 1c). With the latter, the solution flows through the anode, through a small perforation on the brush to avoid particle filtering.

Brush plating conditions.-Coatings of Ni/WC were deposited, although some $\mathrm{Ni}$ and $\mathrm{Ni} / \mathrm{Al}$ samples were produced for comparison purposes. The SIFCO Process was followed to deposit a nickel metallic matrix on a mild steel substrate designation S275JR defined in standard BS EN 10025-2: 2011. For wear testing using the Taber test, Taber S-16 mild steel panels ${ }^{29}$ were used.

Table I outlines the solutions and conditions used for cleaning and activating the surface. All solutions are industrial products manufactured by SIFCO ASC (US) and are listed in Table I. A thin layer $(2 \mu \mathrm{m})$ of nickel was deposited by brush plating in the pre-plating step and the main plating was carried out with a nickel sulfate bath either particle free or with WC particles (diameter 5.9-6.3 $\mu \mathrm{m}$, supplied by William-Rowland, UK). The amount of particles suspended in the solution will be referred as "bath load", which was 20 or $50 \mathrm{~g} / \mathrm{l}$ for low and high bath loads, respectively. The plating solution was recirculated using the setup described in the previous section.

Coated areas are $30 \times 30 \mathrm{~mm}, 50 \times 50 \mathrm{~mm}$ and, for the Taber wear test panels, $100 \times 100 \mathrm{~mm}$. The coating thickness was controlled by measuring the total current applied with the rectifier's Ampere-hour counter, aiming for $80 \mu \mathrm{m}$. The current density used was 75 or 124 $\mathrm{A} / \mathrm{dm}^{2}$, depending on the sample.

$\mathrm{Ni} / \mathrm{WC}$ samples are identified following the code:

$$
\text { XY-n_m (e.g. : AR-75_1) }
$$

- $\mathrm{X}$ is the circulation setup used: magnetically-stirred setup with the solution flow coming from the side of the sample (S) or from the anode center (C); air-stirred setup with the solution flow coming from anode center (A).

- $\mathrm{Y}$ is the Scotch-Brite grade used as the brush material: white (W), red (R), purple (P).

- $\mathrm{n}$ is a number corresponding to the current density used in $\mathrm{A} / \mathrm{dm}^{2}$ (75 or 124).

- $\mathrm{m}$ is the sample number repeat ( 1 or 2 ), for cases where two samples are produced with the same conditions.

\begin{tabular}{|c|c|c|c|}
\hline Step & Solution & Composition (wt.\%) & Conditions \\
\hline \multirow{3}{*}{ Surface preparation } & Electrocleaning & $\begin{array}{l}3 \% \text { Sodium Citrate } \\
2 \% \text { Sodium Hydroxide }\end{array}$ & $15 \mathrm{~V}$ \\
\hline & Etching & $\begin{array}{l}11 \% \text { Sodium Chloride } \\
2 \% \text { Hydrochloric Acid }\end{array}$ & $9 \mathrm{~V}$, reverse current \\
\hline & $\begin{array}{l}\text { Etching and } \\
\text { Desmutting }\end{array}$ & $\begin{array}{l}\text { 15\% Sodium Citrate } \\
6 \% \text { Citric Acid }\end{array}$ & $15 \mathrm{~V}$, reverse current \\
\hline Pre-plating & Nickel Special & $\begin{array}{l}21 \% \text { Nickel Sulfate } \\
4 \% \text { Citric Acid } \\
2 \% \text { Hydrochloric Acid } \\
2 \% \text { Acetic Acid }\end{array}$ & $10 \mathrm{~V}, 2 \mu \mathrm{m}$ thick \\
\hline Plating & Nickel High Speed & $\begin{array}{l}11 \% \text { Nickel Sulfate } \\
10 \% \text { Ammonium Formate } \\
5 \% \text { Ammonium Citrate } \\
4 \% \text { Ammonia Hydroxide }\end{array}$ & 75 or $124 \mathrm{~A} / \mathrm{dm} 2$ \\
\hline
\end{tabular}


(a)

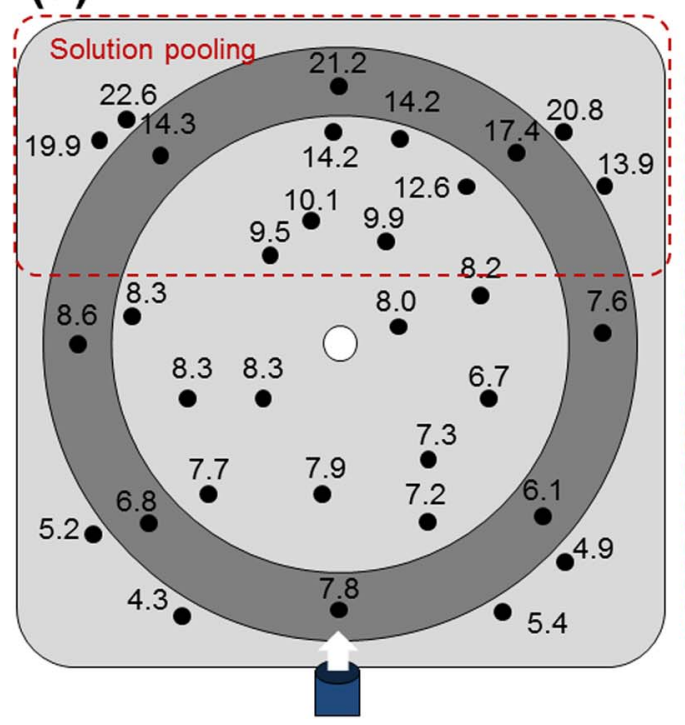

(b)

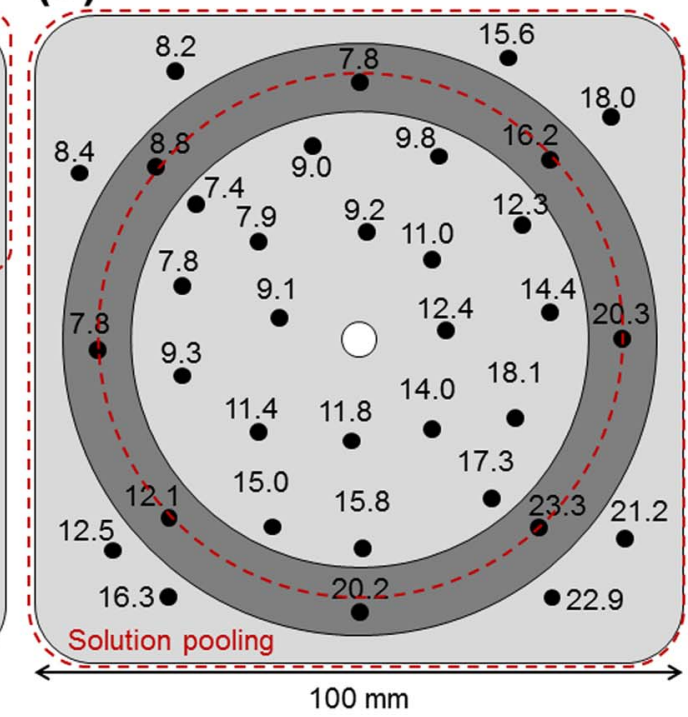

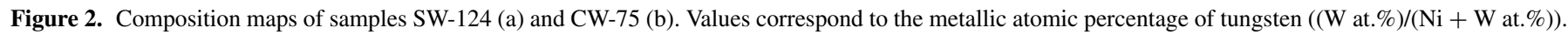

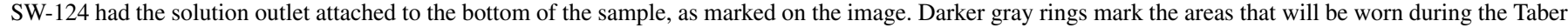
abrasive test, and discontinuous red lines delimit areas where solution pooling was noticed.

Coating characterization.-The coating surface morphology was examined using an FEI XL30 ESEM scanning electron microscope (SEM) using secondary electrons and back-scattered detectors. In all cases, images were taken with $20 \mathrm{kV}$ at a working distance of $11 \mathrm{~mm}$. Cross-sections of the samples were examined using a Nikon Eclipse ME600 reflective optical microscope, with the images captured and thickness measurements undertaken using Leica Application Suite (LAS) software. An Olympus Lext OLS3100 confocal scanning laser microscope was used to map $640 \times 480 \mu \mathrm{m}$ of the surface of the coatings in $3 \mathrm{D}$; from this map, ten random profiles were obtained to calculate average roughness $R_{a}$ parameter and Abbott-Firestone curves.

Composition was determined by X-ray fluorescence (XRF) using a Fischer instrument model XDL-Z and XAN252. A number of measurements from XRF were confirmed by using calibrated energy dispersive X-ray spectroscopy (EDS) with Oxford Instruments Aztec software on flat, $1547 \times 1160 \mu \mathrm{m}$ areas. All composition measurements reflect the atomic percentage (at.\%) of tungsten (W), with the remainder Ni. It is assumed that WC has not dissociated (no evidence was found suggesting otherwise) and that for every atom of $\mathrm{W}$, an atom of $\mathrm{C}$ is present. For each $\mathrm{Ni} / \mathrm{WC}$ sample, a composition map of the plated surface was built from 32-35 random selected points measured with XRF, including 8 points on the future wear track location.

Wear tests.-Abrasive wear resistance was quantified by applying the Taber test using Taber Abraser Models 174 and 5135. ${ }^{30}$ Two CS 17 abrasive wheels abrade the sample surface (on a rotating disk) each with a contacting load of $1 \mathrm{~kg}$. Every full rotation of the disk counts as one cycle. After 1,000 cycles the sample is weighed and the abrasive wheels are re-ground with abrasive silicon carbide paper grade 150 for 100 cycles. The total duration was 15,000 cycles.

For every 1,000 cycles, a partial Taber Wear Index is produced following Equation 1.

$$
T W I_{p}=\frac{w_{i}-w_{f}}{n} \cdot 1000
$$

Where $w_{i}$ is the initial weight of the sample $(\mathrm{mg}), w_{f}$ is the final weight of the sample after the 1,000 cycles $(\mathrm{mg})$, and $n$ is the number of cycles performed between both weigh measurements $(1,000)$. Partial Taber Indexes are usually higher for the first few thousands of cycles, depending on the roughness of the surface: rough surfaces present a reduced contact area between the wheels and the sample, thus exerting a higher pressure on the surface (as the force applied is constant due to the $1 \mathrm{~kg}$ load) and abrading more material. Eventually, the abrasive wheels produce wear the sample surface to an even roughness value, and the material loss stabilizes. Here, this was achieved after 7,000 cycles. The reported Taber Wear Index of each sample was calculated by averaging the partial Taber Wear Indexes between cycles 7,000 to 15,000 .

\section{Results}

Composition mapping.-The distribution of particles in the composite coating was evaluated using two batches of samples: the first to analyze the effect of solution flow direction and current density, the second to analyze the impact of the brush material.

The first batch of samples was produced using the magneticallystirred setup and white brush material, which in previous studies ${ }^{28}$ produced composite coatings with high particle content. Three samples were produced using a bath load of $50 \mathrm{~g} / \mathrm{l}$ :

- SW-75: solution flowing from the sample side and a current density of $75 \mathrm{~A} / \mathrm{dm}^{2}$.

- SW-124: solution flowing from the sample side and a current density of $124 \mathrm{~A} / \mathrm{dm}^{2}$.

- CW-75: solution flowing from the anode center and a current density of $75 \mathrm{~A} / \mathrm{dm}^{2}$.

During plating, it was noticed that the solution flow slows down as it travels away from the tube outlet, eventually stopping (pooling up). The pooling occurs naturally when brush plating large areas, as the surface being plated is often horizontal and facing up. Because the anode area does not cover the whole area to plate, the solution flow slows down as it travels away from the tube outlet, becoming stationary and pooling up on some areas. In this case, pooling was noticed on areas opposite from the solution outlet on samples with solution flowing from the side, and along all sample edges in samples with the solution outlet attached to the anode (see Figure 2).

After the coatings were deposited, XRF measurements were taken to produce a composition map. Coatings SW-75 and SW-124 show a marked gradient of $\mathrm{W}$ composition, increasing in $\mathrm{W}$ content as the distance from the point of solution egress increased as shown in 

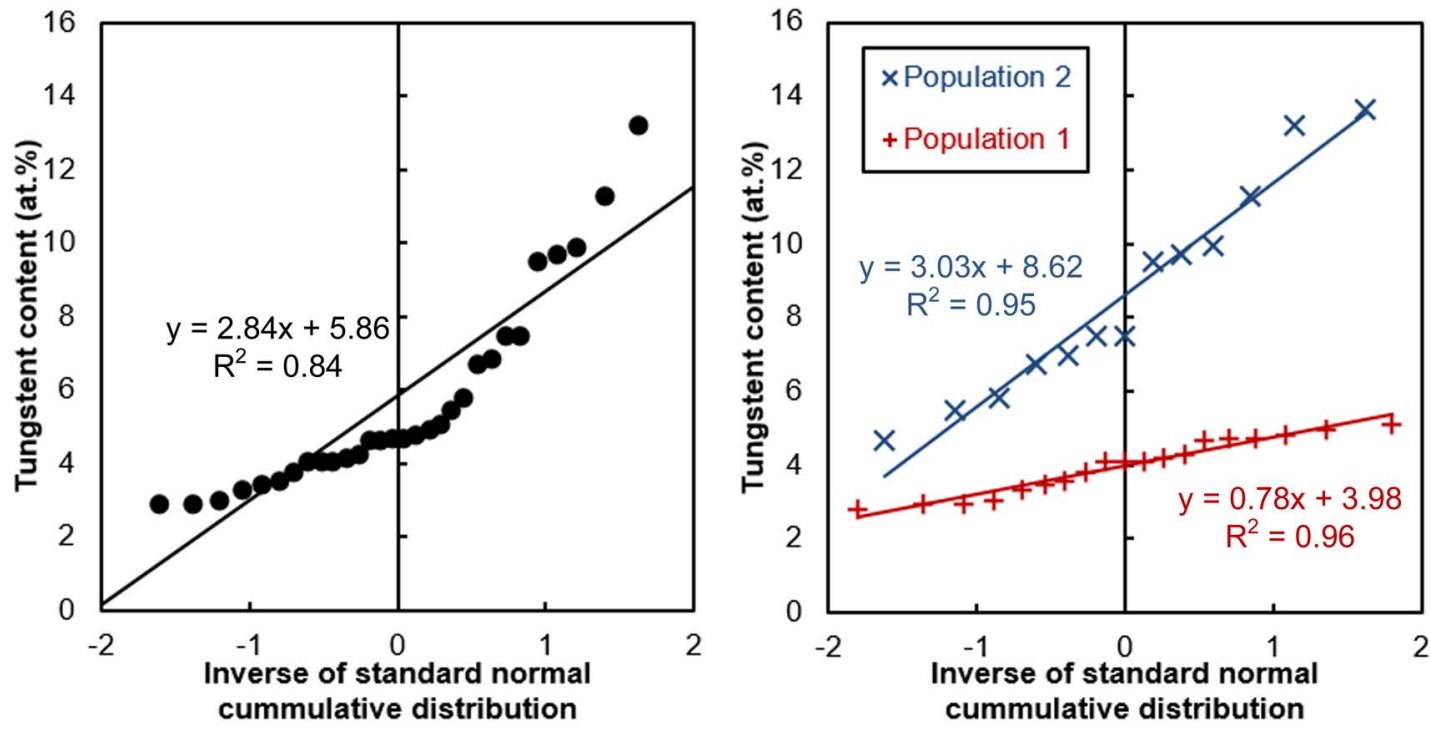

Figure 3. Statistical analysis of sample SW-75. The composition, as tungsten (at.\%), is plotted against the inverse of the standard normal cumulative distribution; for any normal distribution, a straight line can be fitted with a high $\mathrm{R}^{2}$ value $(>0.90)$. (a) plots the composition as a single population, which does not follow a normal distribution, whereas (b) splits the measurements in two different populations that each follows a standard distribution.

Figure 2a. The gradient on sample CW-75 is similar to SW-75 and SW-124 in value, although the pattern is radial centered in the upper left corner (Figure 2b), with W content increasing with the distance from that corner. Pooling was noticed.

A statistical analysis of the composition shows that, for each sample, the measurements follow two distinct normal distributions, as illustrated in Figure 3. For each population, the mean and standard deviation was calculated and is given in Table II. Table II also reports the coefficient of variation, to accurately quantify the composition homogeneity and to compare homogeneity between samples with different composition means. For all samples, Population 2 corresponds to areas where pooling is observed and demonstrates both a higher composition average and coefficient of variation. On the other hand, areas from Population 1 had continuous flow and present a lower, more homogeneous (smaller coefficient of variance) tungsten content.

Table II shows increased W associated with higher current densities between coatings SW-75 and SW-124. Comparing the flow direction at $75 \mathrm{~A} / \mathrm{dm}^{2}$, a slightly higher incorporation of particles is seen when the solution emerges from the center of the moving anode $(\mathrm{CW}$ 75) than when the solution egresses from the sample side (SW-75). Additionally, the solution flowing from the anode produced more homogeneous coatings than when flowing from the side of the sample. The high current density, $124 \mathrm{~A} / \mathrm{dm}^{2}$, produced similar, perhaps a slightly increased, composition variation compared to the low current density, $75 \mathrm{~A} / \mathrm{dm}^{2}$.

Taber wear tests produced early coating failure on all three samples, in all cases located in areas where the tungsten concentration was enriched; more detail can be found in subsequent sections. To avoid high particle content, coated samples were deposited with a lower bath load $(20 \mathrm{~g} / \mathrm{l})$, with the solution outlet attached centrally to the anode and a current density of $75 \mathrm{~A} / \mathrm{dm}^{2}$. The compressed-air stirred setup was used to evaluate the effect of the brush material:

- White Scotch-Brite to deposit AW-75.

- Red Scotch-Brite to deposit AR-75_1 and AR-75_2.

- Purple Scotch-Brite to deposit AP-75_1 and AP-75_2.

Solution pooling was noticed again during plating around the edge of the samples, on the same areas as sample CW-75, as seen in Figure 4. Figure 4 also shows the XRF measurements for the white and red brush material (AW-75 and AR-75_1). In all cases, the radially distributed pattern is similar to CW-75, emanating from the sample center, with W content increasing with increasing distance from sample center. Pooling was more pronounced on the edges, coinciding with higher tungsten content areas. Two distinct normal distributions were found within the sample measurements (see Table II), with population 2 corresponding to areas where pooling was noted with an increased mean W content and coefficient of variation compared to population 1. Different brush materials of the brush produced differences in coating composition. Non-abrasive (white) cloth produced composites with larger amounts of particles, whereas abrasive cloths produced more homogeneous coatings considering both the variance within each population and the difference between population means (the lower mean for AR and AP samples is 46-59\% of the higher mean, whereas the mean in population 1 of AW-75 is only $37 \%$ of

Table II. Characteristic parameters of the two composition populations for the samples.

Composition Population 1

\begin{tabular}{cllc} 
& Sample & Average (at.\% of W) & Coefficient of variatio \\
\cline { 3 - 4 } Batch 1 & SW-75 & $4.0 \pm 0.7$ & $19 \%$ \\
& SW-124 & $7.3 \pm 1.5$ & $20 \%$ \\
& CW-75 & $9.4 \pm 1.6$ & $17 \%$ \\
Batch 2 & AW-75 & $4.9 \pm 1.6$ & $19 \%$ \\
& AR-75_1 & $3.0 \pm 0.8$ & $27 \%$ \\
& AR-75_2 & $3.3 \pm 0.3$ & $9 \%$ \\
& AP-75_1 & $1.7 \pm 0.2$ & $10 \%$ \\
& AP-75_2 & $2.2 \pm 0.2$ & $11 \%$
\end{tabular}

Composition Population 2

\begin{tabular}{cl}
\hline Average (at. $\%$ of W) & Coefficient of variation \\
\hline $8.6 \pm 2.9$ & $33 \%$ \\
$14.5 \pm 5.3$ & $36 \%$ \\
$17.3 \pm 3.4$ & $20 \%$ \\
$13.3 \pm 4.2$ & $31 \%$ \\
$6.6 \pm 3.3$ & $49 \%$ \\
$5.6 \pm 2.2$ & $40 \%$ \\
$3.6 \pm 0.6$ & $18 \%$ \\
$3.6 \pm 0.5$ & $14 \%$
\end{tabular}


(a)

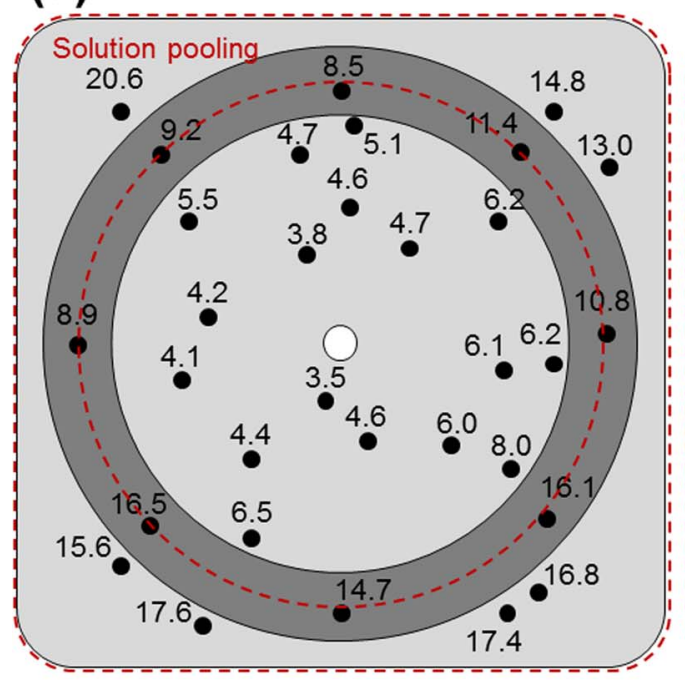

(b)

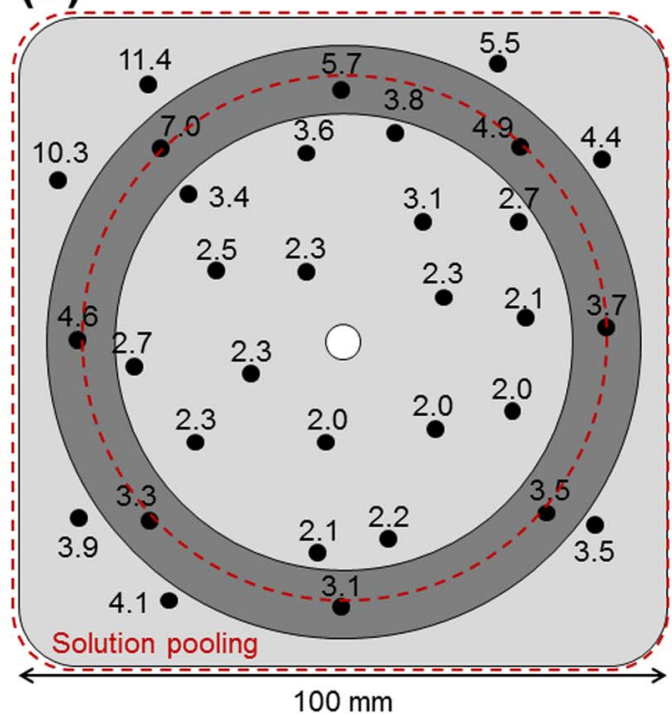

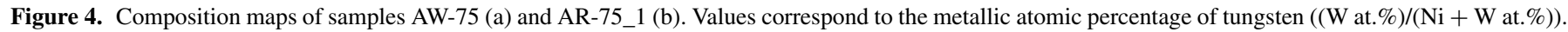

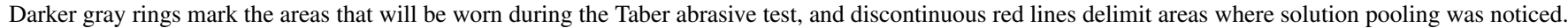

the mean of population 2). The purple cloth was especially effective in reducing the coefficient of variation to $10-11 \%$ in population 1 areas (sample center) and 14-18\% in population 2 areas (high particle content, edges of the sample).

Coating morphology.-The morphology of the Ni/WC coatings shows important differences from pure Ni coatings produced with the same Nickel High Speed solution, as well as from other composite systems such as Ni/Al. Figures 5 and 6 compare the coating surfaces of $\mathrm{Ni}$ and $\mathrm{Ni} / \mathrm{WC}$ produced with the same electroplating conditions. All systems show the globular structure typical of Nickel High Speed, but the size of $\mathrm{Ni} / \mathrm{WC}$ nodules are significantly smaller than the $\mathrm{Ni}$ nodules sizes. For pure Ni coatings, globules are much larger and more defined for non-abrasive coatings, whereas high current densities show an increase of pore size on the surface.

The Ni/WC system shows a similar globule size and shape regardless of the brush material used, with slightly smaller globules on
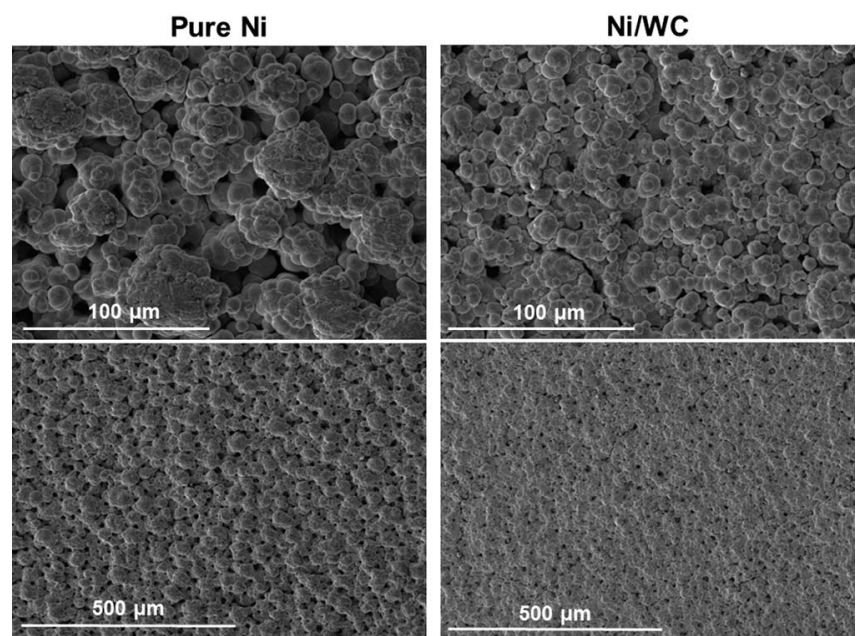

Figure 5. Each column corresponds to a pair of SEM images (secondary electrons detector, top pictures at higher magnification) of the surface of $\mathrm{Ni}$ (left) and Ni/WC (right) coatings, all produced with red abrasive brush material and current density of $75 \mathrm{~A} / \mathrm{dm}^{2}$ (conditions of samples AR-75). coatings deposited with high current densities. These visual observations are backed up by roughness measurements, which give very similar $\mathrm{R}_{\mathrm{a}}$ values for different brush materials but some difference with current density (see Table III). The main feature changing with the coating morphology of $\mathrm{Ni} / \mathrm{WC}$ are the pores, which are both greater in quantity and smaller in size for the high current density coating.

From the surface profiles used to calculate $R_{a}$, Abbott-Firestone (A-F) curves were also produced as per BS EN ISO 13565-2-1998. The A-F curves are produced by integrating the profile's height (i.e., the cumulative probability density function of the height), thus giving information of the relative abundance and height of peaks and valleys. The curves can be characterized by 6 parameters, which are illustrated in Figure 7: material portion of the peaks $\left(\mathrm{M}_{\mathrm{r} 1}\right)$, reduced peak height $\left(R_{\mathrm{pk}}\right)$, area of the peaks $\left(\mathrm{A}_{1}\right)$, material portion of the valleys $\left(\mathrm{M}_{\mathrm{r} 2}\right)$, reduced valley height $\left(R_{v k}\right)$, area of the valleys $\left(A_{2}\right)$. The results are included in Table III and register the same difference as the visual inspection and $\mathrm{R}_{\mathrm{a}}$ calculations: the area corresponding to the valleys
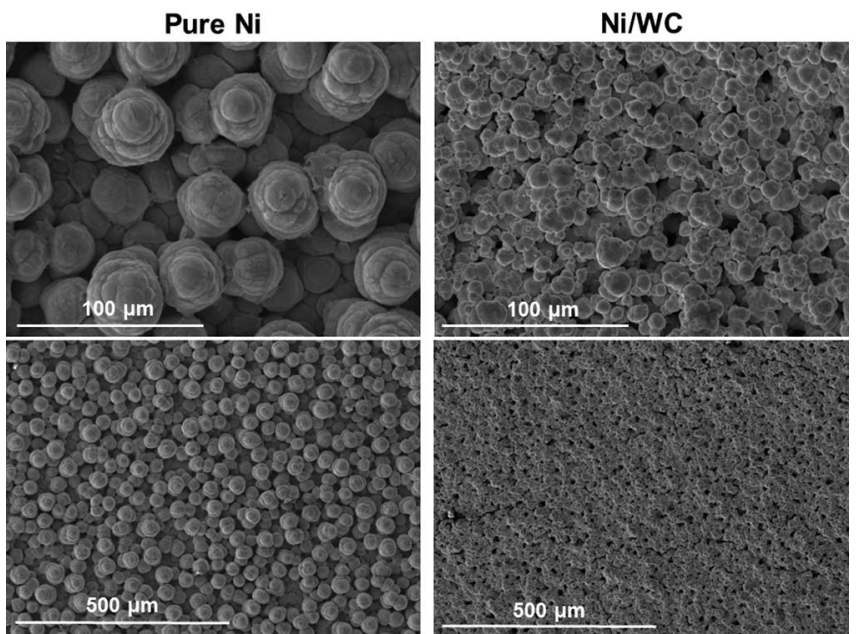

Figure 6. Columns correspond to pairs of SEM images (secondary electrons detector, top pictures at higher magnification) of the surface of $\mathrm{Ni}$ (left) and $\mathrm{Ni} / \mathrm{WC}$ (right) coatings, all produced with white non-abrasive brush material and current density of $75 \mathrm{~A} / \mathrm{dm}^{2}$ (conditions of sample AW-75). 
Table III. Characterization of surface roughness of several Ni/WC samples.

\begin{tabular}{lllll} 
& SW-75 & SW-124 & AW-75 & AR-75_1 \\
\hline $\mathrm{R}_{\mathrm{a}}(\mu \mathrm{m})$ & $2.8 \pm 0.2$ & $2.5 \pm 0.5$ & $3.5 \pm 0.3$ & $3.5 \pm 1.1$ \\
$\mathrm{Mr}_{1}(\%$ of profile $)$ & $12 \pm 1$ & $12 \pm 1$ & $10 \pm 1$ & $3.8 \pm 0.8$ \\
$\mathrm{Mr}_{2}(\%$ of profile) & $91 \pm 1$ & $90 \pm 1$ & $88 \pm 2$ & $9 \pm \pm 1$ \\
$\mathrm{~A} 1(\mu \mathrm{m} \times \%$ profile $)$ & $27 \pm 4$ & $36 \pm 14$ & $22 \pm 2$ & $90 \pm 1$ \\
$\mathrm{~A} 2(\mu \mathrm{m} \times \%$ profile $)$ & $17 \pm 1$ & $18 \pm 3$ & $40 \pm 9$ & $26 \pm 6$ \\
$\mathrm{R}_{\mathrm{pk}}(\mu \mathrm{m})$ & $4.5 \pm 0.4$ & $5.5 \pm 1.8$ & $4.4 \pm 0.4$ & $25 \pm 10$ \\
$\mathrm{R}_{\mathrm{vk}}(\mu \mathrm{m})$ & $3.5 \pm 0.2$ & $3.6 \pm 0.6$ & $6.3 \pm 0.8$ & $4.8 \pm 1.1$ \\
\end{tabular}

$\left(\mathrm{A}_{2}\right)$ for the SW-124 coating is approximately half the area of the peaks $\left(\mathrm{A}_{1}\right)$, whereas for $\mathrm{AW}-75$ the opposite is true.

When comparing the Ni/WC system to another composite system $(\mathrm{Ni} / \mathrm{Al})$, there are differences with particle visibility at the surface. The particle size is of the same order of magnitude and both coatings have comparable amounts of embedded particles, according to both

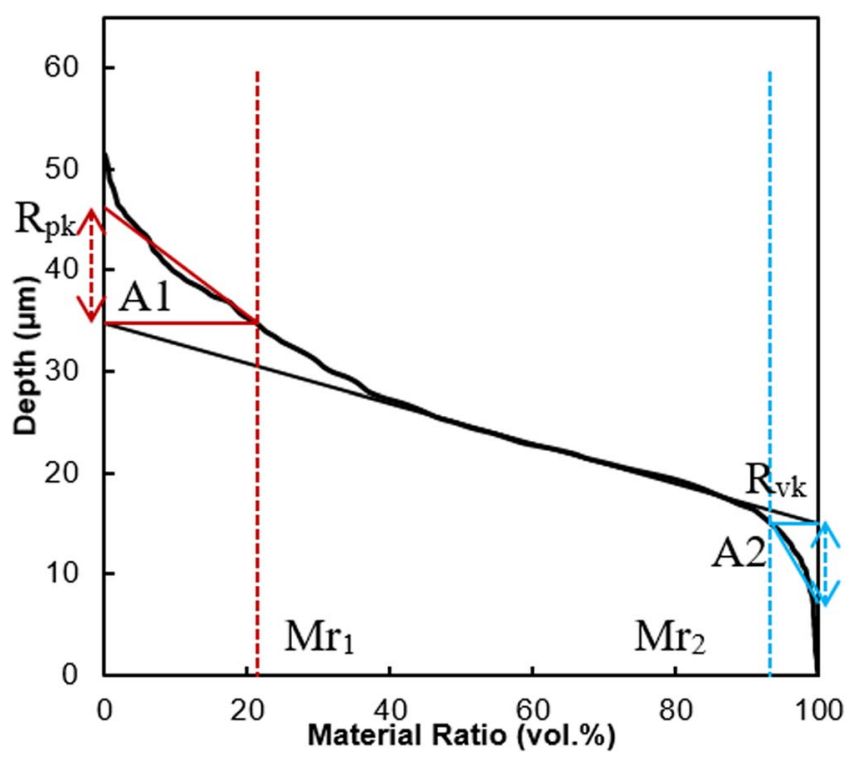

Figure 7. Diagram showing an Abbott-Firestone curve example and its characteristic parameters.

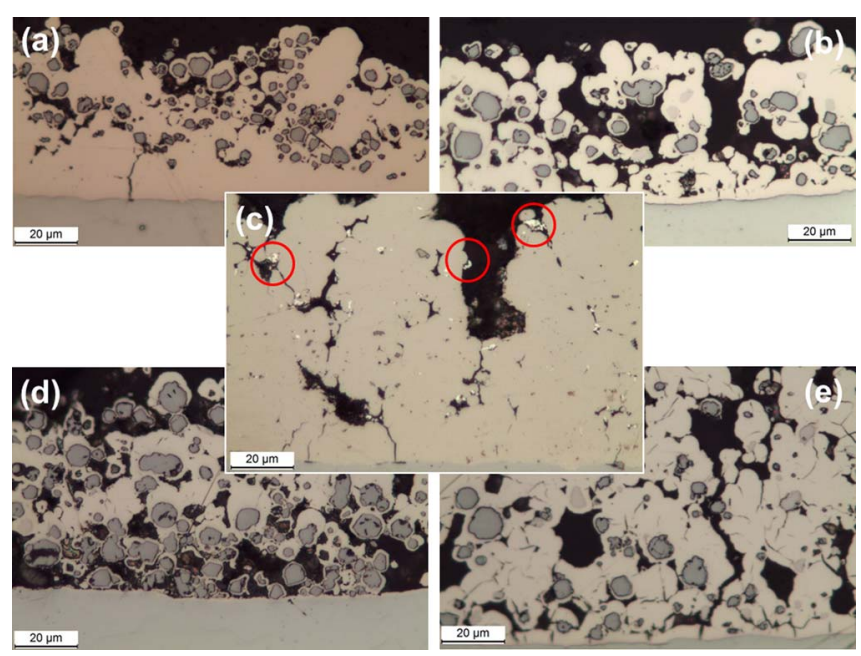

Figure 8. Cross-section images of Ni/WC samples (a) SW-124, (b) AP-75_1, (d) AW-75, and (e) AP-75. Image (c) corresponds to a Ni/Al coating deposited using white brush material at $124 \mathrm{~A} / \mathrm{dm}^{2}$; it can be seen that many Al particles (circled in red) are not fully covered by nickel.
XRD and EDX measurements. The Al particles are easily visible on the coating surface, whereas the WC particles are much harder to detect. In both cases, the use of a back-scattered detector enhances the contrast between particles and matrix due to the differences in atomic weight between $\mathrm{Ni}, \mathrm{Al}$ and $\mathrm{W}$. Interestingly, cross-section images from Figure 8 show a thin layer of Ni fully covering all WC particles. This phenomenon is not observed in the $\mathrm{Ni} / \mathrm{Al}$ system, where $\mathrm{Al}$ particles do not appear to be fully covered (Figure 8c).

Abrasive wear and coating failure.-The results of Taber wear tests conducted for all samples for 15,000 cycles are given in Table IV. The Taber Wear Index (TWI) is given, where the lower the wear index, the better the abrasion resistance. All samples from the first batch register localized coating failure (example in Figure 9a). On the other hand, all samples from the second batch finished the tests without any signs of coating failure (as shown in Figure 9b) and the resistance to material loss was increased between 1.9 and 3.3 times with respect to the best results from pure $\mathrm{Ni}$ coatings, reaching a similar Taber Wear Index to hard chrome. Inspection of the wear track revealed the different behavior of the two sets of samples. A uniform wear track was observed with the second batch of samples. However, for the first batch of samples, damage on the coating was classified into three parts: no coating failure, mild failure and severe failure.

Table IV. Taber Wear Index (TWI) obtained for diverse samples: reference coatings, such as tank plated hard chrome and brush plated SIFCO products, and Ni/WC coatings.

\begin{tabular}{lll} 
Coating type & Coating & TWI \\
\hline Reference coatings & Hard Chrome-source ${ }^{38}$ & 3.2 \\
& Nickel High Speed 75 A/dm ${ }^{2}$ (SIFCO 5644) & $14-20$ \\
Ni/WC coatings & AW-75 & 6.1 \\
& AR-75_1 & 7.9 \\
& AR-75_2 & 4.5 \\
& AP-75_1 & 7.1 \\
& AP-75_2 & 5.0
\end{tabular}
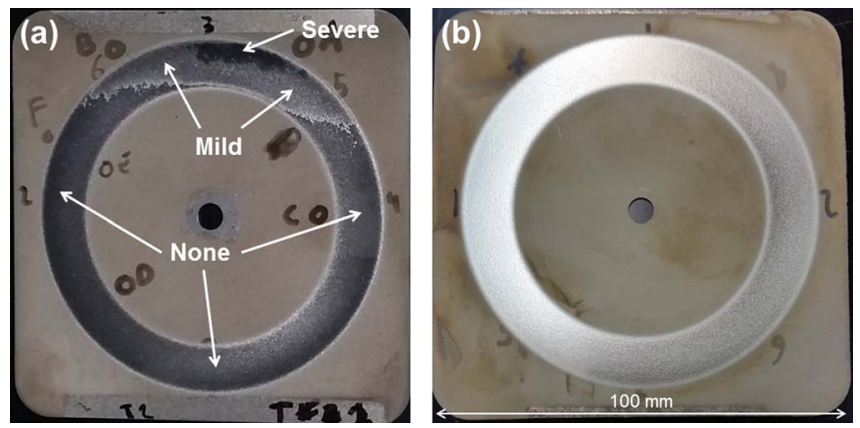

Figure 9. Visual inspection of Taber panels after testing reveals areas with different degrees of coating failure for the first batch, as for sample SW-124 (a); areas have been identified according to degree of damage. Abrasion for the second batch is uniform, as for sample AR-75_2 (b). 

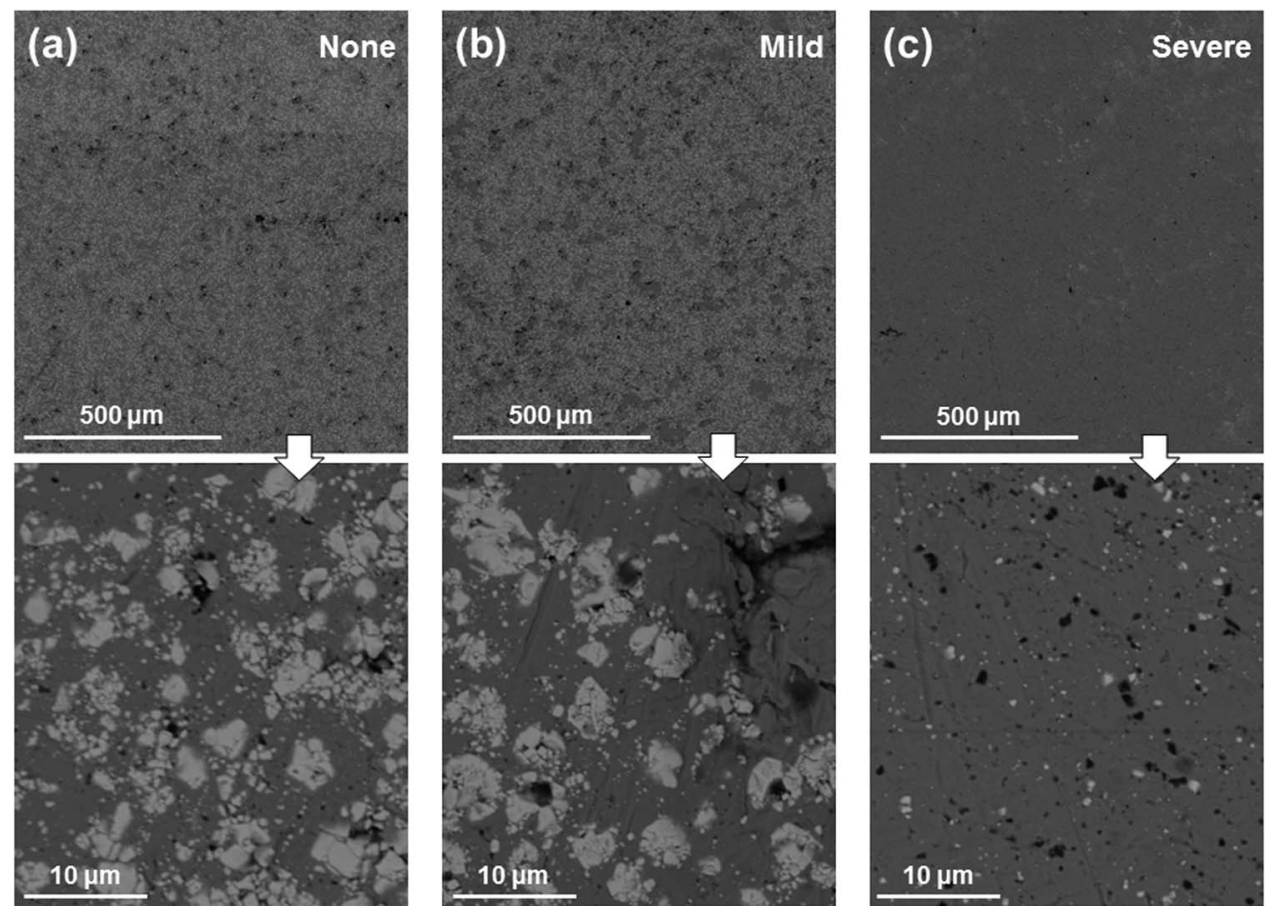

Figure 10. ESEM images from the abraded track surface of SW-124. Each pair of images has been taken with the back-scattered electrons detector at two different magnifications from areas with different degrees coating failure: (a) No failure, (b) Mild failure, (c) Severe failure. Nickel and steel background appears darker due to the lower atomic mass when compared with the tungsten present in light gray WC particles.

Further evaluation of the coating damage was assessed by surface and cross-section microscope inspection.

Surface inspection by ESEM showed little difference between areas where there was mild or no failure; both had a smooth surface where presence of WC particles is more evident than on the as-plated surface. On the contrary, the surface of areas with severe failure lacked the presence of particles or pores, appearing as the substrate material (Figure 10). For further detail, several locations were cross-sectioned to see differences in coating thickness (the border between no failure and mild failure areas, the border between mild and severe failure areas), and to assess as-plated structure of the coatings (the border between the wear track and the as-plated surface for each level of damage, Figure 11). This revealed that the remaining coating within the mild failure area is substantially thinner than areas with no failure (down to $1 / 3$ of the thickness without coating failure), and that the coating was completely stripped on areas with severe damage, except for a few isolated pockets. Cross-sections in Figure 11 show the border between the track and the as-plated surface. Due to the small distance covered by each image $(<1.5 \mathrm{~mm})$ it can be assumed that the structure prior to the wear on the left-hand side of the image was the same as on the structure shown on the right-hand side. Areas of coating that did not fail showed a compact morphology that was Ni-rich, whereas the structures of the mild and severely damaged coating were porous and had a high density of WC particles. Indeed, the latter areas (severely damaged) correspond with the largest $\mathrm{W}$ content, all of them above 13 at. $\%$.

\section{Discussion}

The uniformity and sample composition of Ni/WC coatings have been statistically analyzed and composition maps have been created. To the best of the authors' knowledge, the topic of uniformity of MMC composition within the samples has not been addressed in literature. Composition mapping enabled the link to be made with areas of high particle content associated with liquid 'pooling' during plating, which induces particles to sediment onto the coating surface, thereby increasing the amount of particles incorporated into the coating. The
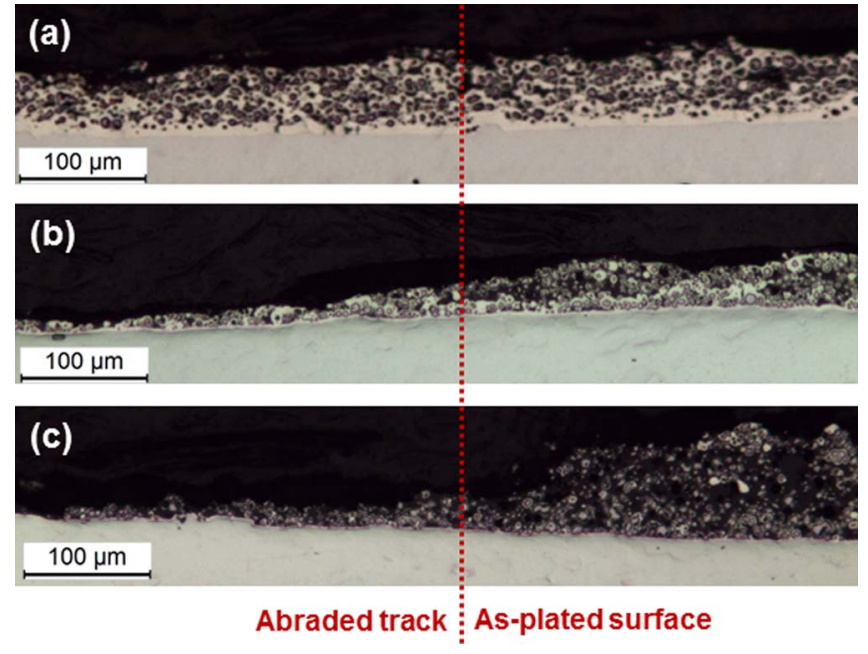

Figure 11. Cross-section images of $\mathrm{Ni} / \mathrm{WC}$ coatings taken at the edge of the abraded track, the left-hand side of the image is associated with the wear track and the right-hand side is located outside of the worn area, retaining the asplated structure. The three images are linked to areas with different degrees of coating damage: (a) no failure of SW-75, (b) mild failure area and (c) severe failure area both of SW-124.

statistical analysis confirms significant differences in particle incorporation due to solution pooling, as all other plating parameters are the same across the surface of the sample. Indeed composition measurements followed two normal distributions with statistically different means and standard deviations one associated with solution pooling and one distribution linked to a more uniform continuous solution flow. Despite producing high particle content areas, pooling seems to be mainly detrimental as it produces poor uniformity and hinders accurate composition control. Composition uniformity improved when solution pooling was reduced. 
The morphology of the composite coatings seems mainly influenced with the WC particles, which is different to the $\mathrm{Ni}$ and $\mathrm{Ni} / \mathrm{Al}$ systems studied in the past. ${ }^{28}$ The morphology of the latter coatings depends mainly on the current density and brush material, while producing very similar structures regardless of the presence of $\mathrm{Al}$ particles. In the case of $\mathrm{Ni} / \mathrm{WC}$, the current density produced small differences and the material of the brush did not have a significant impact. Higher current densities produced slightly smaller nickel globules and significantly smaller but more frequent pores, which may indicate changes due to hydrogen evolution: large concentrations of hydrogen are dispersed throughout the surface. On the other hand, no differences in morphology were observed between abrasive and non-abrasive brush materials. In all cases, the observed $\mathrm{Ni} / \mathrm{WC}$ structure fits with abrasive areas of a Structure Zone Diagram for $\mathrm{Ni} / \mathrm{Al}$ coatings ${ }^{28}$ regardless of the brush material. The WC particles could be acting as the abrasive particles embedded on the brush, producing scratches on the Ni that become nucleation sites for new globules; therefore, the same phenomena would be produced for all brush materials. Moreover, cross-section images of the coating showed that areas rich in WC have many voids in the nickel structure, which is particularly accentuated in areas where severe failure of the coating occurred during abrasion tests. These images also reveal that most WC particles appear completely covered by a thin film of $\mathrm{Ni}$, which may indicate a preferential deposition of $\mathrm{Ni}$ ions on WC surfaces, possibly leading to the non-compact matrix structures described.

In summary, with WC particles present, the coating morphology does not change significantly with plating parameters. High concentrations of WC particles produce coatings with a matrix structure rich in voids, although the particles are covered well by the matrix; this indicates a degree of interaction between $\mathrm{Ni}$ and $\mathrm{WC}$ during coating growth. The reviewed literature for electroplated $\mathrm{Ni} / \mathrm{WC}$ coatings did not record this behavior between matrix and dispersed phase, although the observations of the aforementioned effects can be hindered because, in many cases, the deposited nickel is compact and the particle size was smaller than $6 \mu \mathrm{m}$. However, the Ni-WC interaction is well known for other MMCs: the hard metals or cemented carbides. Cemented carbides are often produced by sintering or by hot isostatic pressing (HIP) and comprise two phases: a matrix, usually $\mathrm{Co}, \mathrm{Ni}$, or a combination of these with $\mathrm{Fe}, \mathrm{Cr}$ and $\mathrm{Mo}$; and dispersed particles of refractory carbides of transition metals (such as WC, TiC, $\mathrm{TaC}){ }^{25,26,31-33}$ The surface energy between both phases is reported to be low (especially $\mathrm{Co}$ or Ni with WC or TiC), ${ }^{26}$ which produces excellent wettability and keeps pores to 0.2 vol.\%. ${ }^{25,34}$ Chemical bonds develop (especially with Co-WC) and produce strong adhesion between the matrix and dispersed phase. ${ }^{26}$ The differences between are striking; for instance, the matrix fuses completely in the case of cemented carbides and partially dissolves $\mathrm{W}$ and $\mathrm{C}$ atoms into the melt, which creates a solid solution upon solidification that increases the matrix hardness. $\mathrm{W}$ and $\mathrm{C}$ matrix enrichment is unlikely during electroplating as temperatures are too low for diffusion to be significant. However, many of the explanations for the chemical bond at the interface between carbides and iron-group metals gathered by Exner $^{26}$ are not related to the solid-liquid transition of the metal, but revolve around electron's energy shift and free-electron concentrations. Some of the affinity between $\mathrm{Ni}$ and $\mathrm{WC}$ can be retained in the case of electroplated MMC, which may explain the preferential coating of the particles. This may also mean a better adhesion between particles and matrix. The nickel deposition can be aided by the relatively good conductivity of the particles (about $1 / 3$ that of the nickel), ${ }^{35}$ which would share the potential of the nickel surface once they are in contact. In fact, successful electrodeposition of nickel onto WC has been reported ${ }^{36}$ and it is not uncommon to use electroless Ni-P to coat WC powder. ${ }^{37}$

Abrasive wear tests reveal both enhanced wear resistance and the failure mechanism of the composite coating. Samples with a moderate concentration of WC particles suffer material loss approaching that of hard chrome coatings, with a reduction of $47-70 \%$ in weight with respect to material loss suffered by the Nickel High Speed deposit. It is worth noting that the Taber Wear Index used in this work is based on weight difference. The volumetric material loss is smaller for the case of $\mathrm{Ni} / \mathrm{WC}$ due to the lower density of chromium $\left(7.2 \mathrm{~g} / \mathrm{cm}^{3}\right)$ when compared to nickel $\left(7.8 \mathrm{~g} / \mathrm{cm}^{3}\right)$ and especially to tungsten carbide $\left(15.6 \mathrm{~g} / \mathrm{cm}^{3}\right)$, which would mean longer-lasting service life for $\mathrm{Ni} / \mathrm{WC}$ coatings of the same thickness as hard chrome ones. On the other hand, excessive concentrations of WC ( $>21.3$ at.\% of W) are detrimental and lead to premature failure of the nickel high speed-based coatings, likely due to the less-compact, void-rich matrix structure produced in areas rich in WC particles. For an average WC particle content below 9.4 at.\% of W, no significant difference is found in the Taber Wear Indexes. This could be due to differences in coating density, as the WC density is twice that of nickel, thus small volumetric losses of WC-rich coatings are offset by the mass of lost material.

Overall, this study points out the effects of process parameters and solution pooling in the composition, morphology and performance of $\mathrm{Ni} / \mathrm{WC}$ coatings. With the right set of parameters, the coating performance can be closer to that of hard chrome. Further studies with larger numbers of samples are required to assess the reproducibility of the process and to optimize the coating for commercial use.

\section{Conclusions}

$\mathrm{Ni} / \mathrm{WC}$ composite coatings were successfully deposited and characterized. Both the direction of the solution flow and solution 'pooling' influence the distribution of particles within the plating. Attaching the tube outlet to one side of the sample produced a linear particle distribution, with particle volume increasing as the distance to the solution outlet increases. An outlet attachment to the anode gives a circular particle distribution increasing in concentration from the center outwards. In both cases, areas where solution 'pooling' occurs result in high particle content in the coating and large composition variance, whereas minimising solution 'pooling' gives areas with lower particle content and a narrow composition range. This latter situation is more desirable for improved wear resistance.

Increasing the current density increases concentration of particles on the coating and slightly affects the matrix morphology by reducing the globular and pore size. For all current densities and brush materials, thin Ni deposits covered most WC particles. The use of different brush materials alters the coating composition, but not the matrix morphology. Non-abrasive brushes produce coatings with large average particle content and also large composition variance. Three samples with areas of high particle content $(>21.3$ at. $\% \mathrm{~W}$ ) showed premature coating failure during abrasive wear testing. On the other hand, abrasive brushes producing homogeneous coatings with low average particle content did not show premature coating failure. An optimal composition, 2.6-10.2 at.\% $\mathrm{W}$, has wear resistance 1.8-4.4 times higher than the original Ni matrix.

\section{Acknowledgments}

This research has been funded jointly by Cranfield University and SIFCO Applied Surface Concepts under an Industrial Doctorate Scheme. The authors acknowledge the help of Prof. John Nichols with the statistical treatment of the composition measurements, as well as the support received from the whole team of SIFCO ASC Cleveland, in particular from Darrin K. Radatz regarding the air-stirred setup.

\section{ORCID}

\section{J. L. Endrino (1D https://orcid.org/0000-0002-3084-7910}

\section{References}

1. M. Schlesinger and M. Paunovic, Modern Electroplating, John Wiley \& Sons, New Jersey (2010).

2. Z. Zhong and S. J. Clouser, Surf. Coatings Technol., 240, 380 (2014).

3. M. Srivastava, C. Anandan, and V. K. W. Grips, Appl. Surf. Sci., 285, 167 (2013).

4. A. A. Aal, K. M. Ibrahim, and Z. A. Hamid, Wear, 260(9), 1070 (2006) 
5. H. Gül et al., Appl. Surf. Sci., 258(10), 4260 (2012).

6. M. Surender, B. Basu, and R. Balasubramaniam, Tribol. Int., 37(9), 743 (2004).

7. J. P. Celis, J. R. Roos, and C. Buelens, J. Electrochem. Soc., 134(6), 1402 (1987)

8. C. Kerr, D. Barker, F. Walsh, and J. Archer, Trans. Inst. Met. Finish., 78(5), 171 (2000).

9. H. Matsuda, M. Nishira, Y. Kiyono, and O. Takano, Trans. Inst. Met. Finish., 73(1), 16 (1995).

10. Y. Wang, X. F. Cui, G. Jin, H. P. Li, W. Zheng, and X. M. Zhang, Adv. Mater. Res., 936, 1025 (2014).

11. Y. X. Shang and X. M. Zhang, in Material Science and Environmental Engineering. Proceedings of the 3rd annual 2015 International Conference on Material Science and Environmental Engineering, ICMSEE 2015, 219 (2016).

12. J. Man, S. Zhang, J. Li, B. Zhao, and Y. Chen, Surf. Coatings Technol., 249, 118 (2014).

13. B. Wu, B. S. Xu, B. Zhang, and Y. H. Lü, Surf. Coatings Technol., 201, 6933 (2007)

14. H. Xiao and S. Clouser, in National Association for Surface Finishing Annual Conference and Trade Show 2010, SUR/FIN 2010, 1, 95 (2010).

15. J. C. Norris, Met. Finish., 93(1), 349 (1995).

16. R. D. Clarke, Int. J. Adhes. Adhes., 19(2), 205 (1999)

17. D. Vanek, Met. Finish., 100(7), 180 (2002).

18. D. Vanek, Met. Finish., 108(9), 25 (2010).

19. B. Wu, B. Xu, B. Zhang, X. Jing, and C. Liu, Mater. Lett., 60(13), 1673 (2006).

20. J. Man, S. Zhang, X. Luan, Y. Hai, and G. Cai, Int. J. Precis. Eng. Manuf. Technol., 4(1), 19 (2017)

21. M. Tyrrell, in Aerosp. Manuf., The evolution of automatic plating (2017)

22. W. H. Li, X. Y. Zhou, Z. Xu, and M. J. Yan, Surf. Coatings Technol., 201, 1276 (2006)
23. J. W. Dini, Met. Finish., 95(6), 88 (1997).

24. X. Fang, G. Jin, X. F. Cui, and J. N. Liu, Surf. Coatings Technol., 305, 208 (2016)

25. G. S. Upadhyaya, Mater. Des., 22(6), 483 (2001).

26. H. E. Exner, Int. Met. Rev., 24(1), 149 (1979).

27. $3 \mathrm{M}$, Scotch-Brite hand pad 7445. Available at: https://www. 3 m.com/3 M/en_US/ company-us/all-3m-products/ $/$ Scotch-Brite-Light-Cleansing-Hand-Pad-7445? $\mathrm{N}=$ $5002385+3293194061 \& \mathrm{rt}=$ rud (Accessed: 11 December 2017).

28. L. Isern, S. Impey, H. Almond, S. J. Clouser, and J. L. Endrino, Sci. Rep., 7, 44561 (2017).

29. Taber Industries, Taber test accessiories. Available at: http://www.taberindustries .com/taber-test-accessories (Accessed: 11 December 2017).

30. ASTM D4060-10, Standard Test Method for Abrasion Resistance of Organic Coatings by the Taber Abraser, ASTM International, West Conshohocken, PA, (2010).

31. G. S. Upadhyaya, Cemented Tungsten Carbides. Production, Properties and Testing, p. 7, William Andrew, New York (1998).

32. C. M. Fernandes and A. M. R. Senos, Int. J. Refract. Met. Hard Mater, 29(4), 405 (2011).

33. G. S. Upadhyaya, in Cemented Tungsten Carbides. Production, Properties and Testing, p. 166, William Andrew, New York (1998).

34. G. S. Upadhyaya, in Cemented Tungsten Carbides. Production, Properties and Testing, p. 138, William Andrew, New York (1998).

35. H. O. Pierson, Handbook of Chemical Vapor Deposition. Principles, Technology and Applications, p. 458, William Andrew, New York (1999).

36. H. A. Wahab, M. Y. Noordin, M. S. Hussain, and S. Izman, Appl. Mech. Mater, 315, 73 (2013).

37. F. Xue, L. Zhu, J. Wang, and Z. Tu, Surf. Coatings Technol., 265, 32 (2015)

38. E. W. Brooman, Galvanotechnik, 96(12), 2843 (2005). 
2018-06-16

\section{Particle distribution, film formation and wear performance of brush plated $\mathrm{Ni} / \mathrm{WC}$}

Isern, Luis

Electrochemical Society

Isern L, Impey S, Clouser SJ. (2018) Particle distribution, film formation and wear performance

of brush plated Ni/WC. Journal of The Electrochemical Society, Volume 165, Issue 9, 2018, pp. D402-D410 Https://doi.org/10.1149/2.1161809jes

Downloaded from Cranfield Library Services E-Repository 